\title{
Structural Implications on the Properties of Self-Assembling Supramolecular Hosts for Fluorescent Guests
}

\author{
Sicheng Tang, ${ }^{\dagger, \S}$ Bryan Donaphon, ${ }^{\ddagger, \S}$ Marcia Levitus ${ }^{*}, \neq$ \\ and Françisco M. Raymo*,†
}

Laboratory for Molecular Photonics, Department of Chemistry, University of Miami, 1301 Memorial Drive, Coral Gables, Florida, 33146-0431 and School of Molecular Sciences and The Biodesign Institute, Arizona State University, Tempe, Arizona, 85287-5601

E-Mail: Marcia.Levitus@asu.edu; fraymo@miami.edu

- DLS Measurements of 1a-1f, 2b and 2c

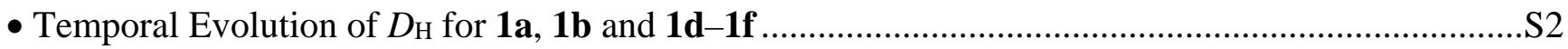

- Temporal Evolution of the Emission Intensity of 6 ........................................................................

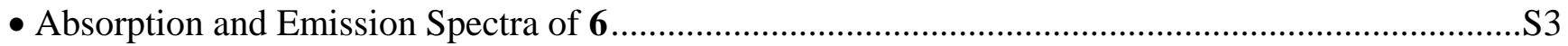

• Fluorescence Decays and Fitting Parameters of 6 ................................................................................ 3

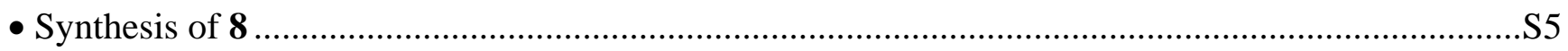

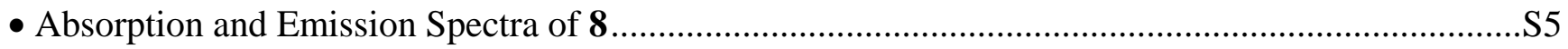

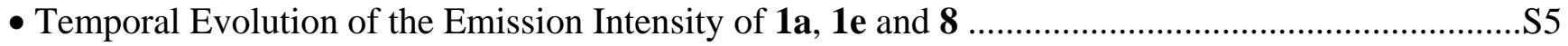

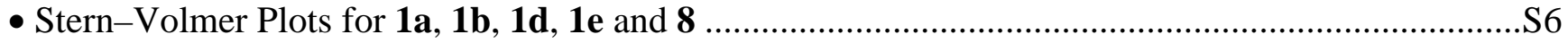

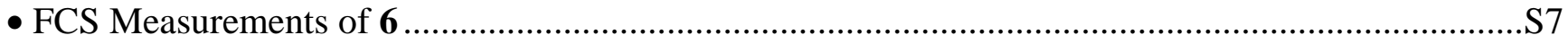

$\dagger$ University of Miami

$\ddagger$ Arizona State University

$\S$ Contributed equally to this work

* Correspondence authors 


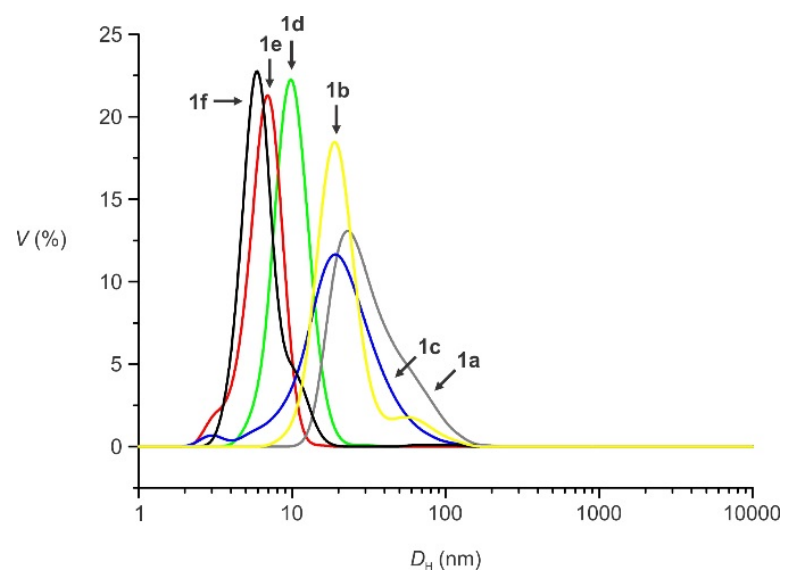

Figure S1. Statistical distributions of $D_{\mathrm{H}}$ for $1 \mathbf{a}-\mathbf{f}(0.5$ $\mathrm{mg} \mathrm{mL} \mathrm{m}^{-1}$ ) determined by DLS in PBS at $22^{\circ} \mathrm{C}$.

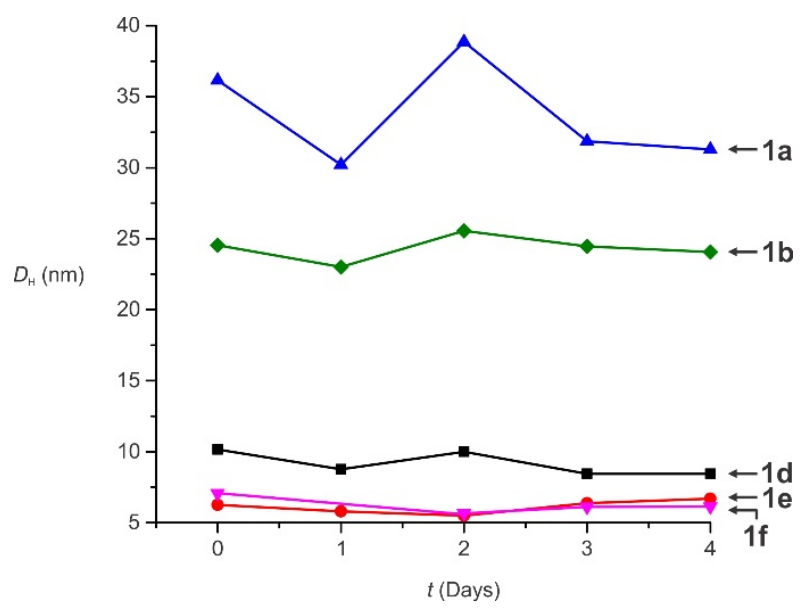

Figure S3. Temporal dependence of $D_{\mathrm{H}}$ for $\mathbf{1 a}, \mathbf{1 b}$ and 1d-f $\left(0.5 \mathrm{mg} \mathrm{mL}^{-1}\right)$ in PBS at $22^{\circ} \mathrm{C}$.

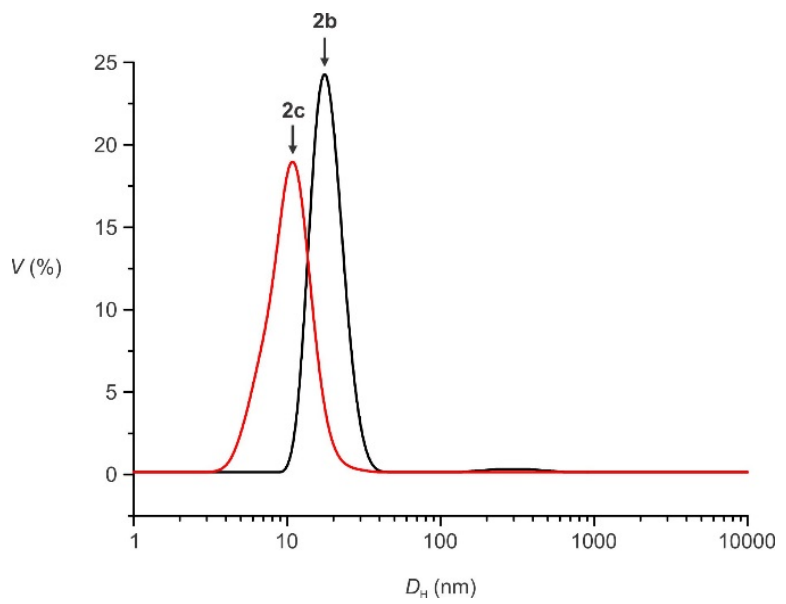

Figure S2. Statistical distributions of $D_{\mathrm{H}}$ for $\mathbf{2 b}$ and $\mathbf{2 c}$ $\left(0.5 \mathrm{mg} \mathrm{mL}^{-1}\right)$ determined by DLS in PBS at $22^{\circ} \mathrm{C}$.

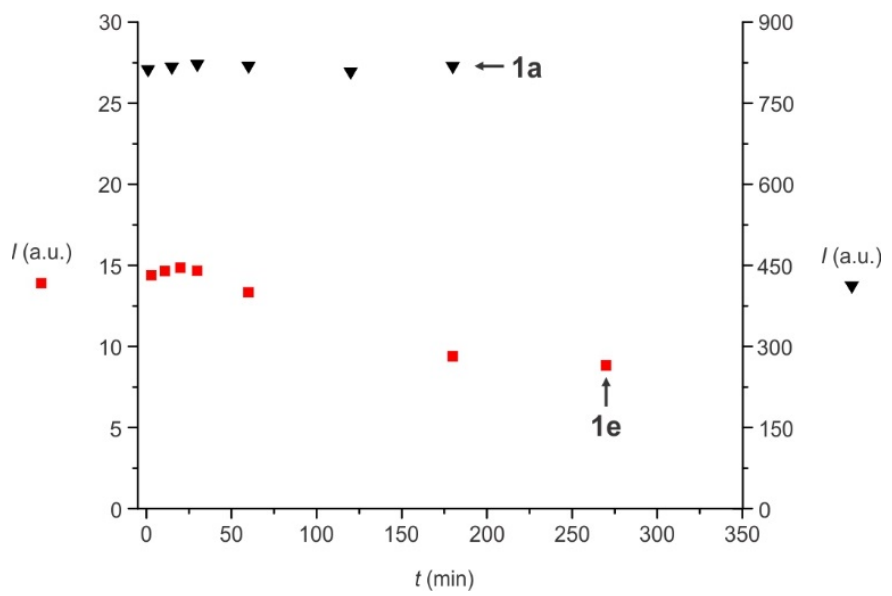

Figure S4. Emission intensity $\left(\lambda_{\mathrm{Ex}}=500 \mathrm{~nm}, \lambda_{\mathrm{Em}}=540 \mathrm{~nm}\right)$ of nanoparticles of either 1a or 1e, containing 6 ( $6.6 \mu \mathrm{M}$ for $\mathbf{1 a}$ and $3.9 \mu \mathrm{M}$ for $1 \mathbf{e}$ ), recorded in PBS at $25^{\circ} \mathrm{C}$. 

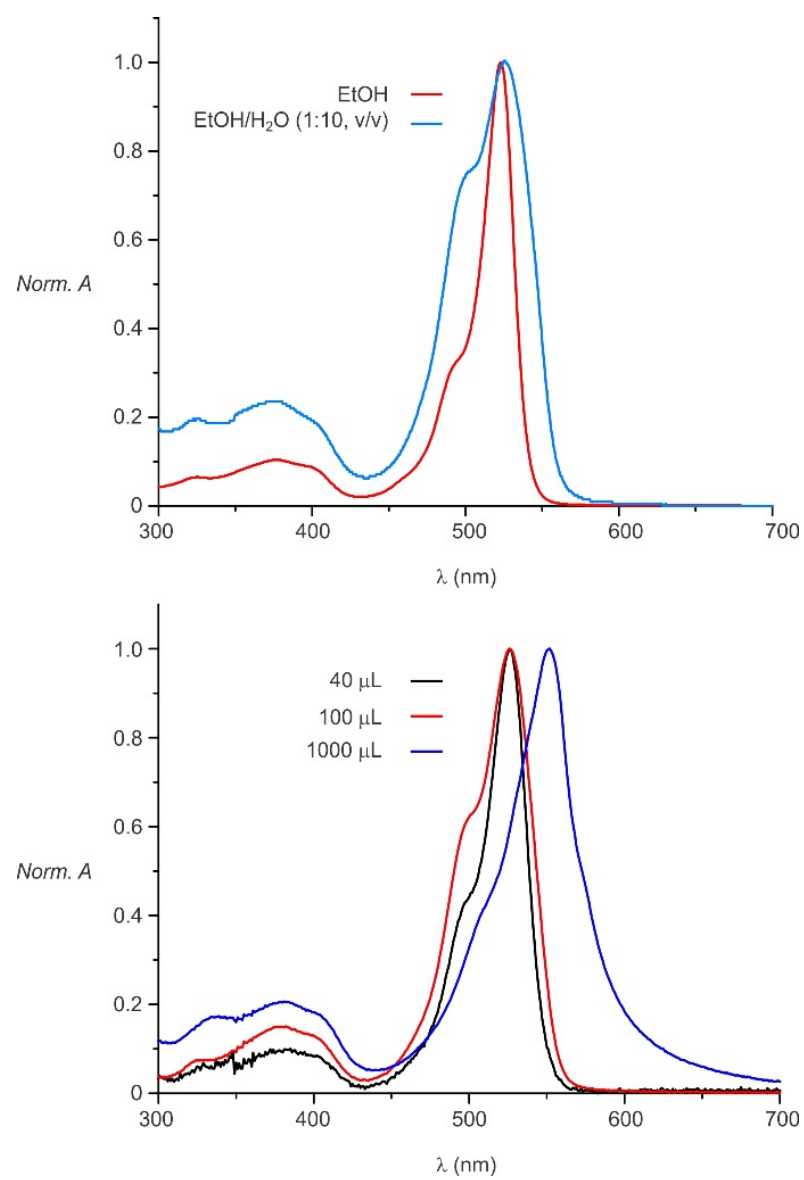

Figure S5. Normalized absorption spectra of $\mathbf{6}$ in EtOH, EtOH/ $\mathrm{H}_{2} \mathrm{O}(1: 10, \mathrm{v} / \mathrm{v})$ or after combining $\mathrm{CH}_{2} \mathrm{Cl}_{2}$ solutions of $6(0.1 \mathrm{mM}$, volume indicated in the chart) and 1 e $(1 \mathrm{mg} \mathrm{mL}-1,0.5 \mathrm{~mL})$, distilling the solvent off under reduced pressure, dispersing the residue in PBS (1 $\mathrm{mL}$ ) and passing the resulting dispersion through a nanoporous membrane.
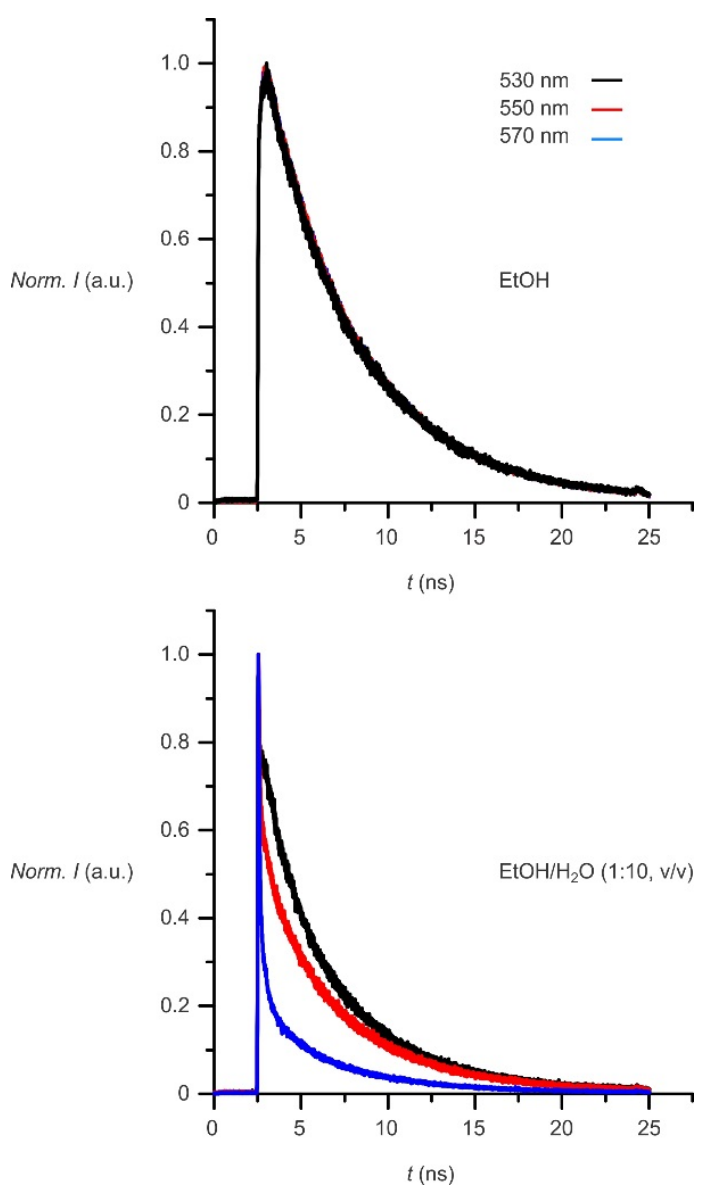

Figure S6. Fluorescence intensity decays $\left[\lambda_{\mathrm{Ex}}=\right.$ $500 \mathrm{~nm}, \lambda_{\mathrm{Em}}=570$ (blue), 550 (red) or $530 \mathrm{~nm}$ (black)] of 6 in $\mathrm{EtOH}$ or $\mathrm{EtOH} / \mathrm{H}_{2} \mathrm{O}(1: 10, \mathrm{v} / \mathrm{v})$. Decays were fitted with a sum of exponentials (Table S1). 
Table S1. Fitting parameters [a] for the fluorescence decays of 6 [b].

\begin{tabular}{|c|c|c|c|c|c|c|c|c|}
\hline & $\begin{array}{c}\lambda_{\text {Ex }} \\
(\mathrm{nm})\end{array}$ & $\begin{array}{c}\lambda_{\mathrm{Em}} \\
(\mathrm{nm})\end{array}$ & $\begin{array}{c}\tau_{1} \\
\text { (ns) }\end{array}$ & $\%$ & $\begin{array}{c}\tau_{2} \\
\text { (ns) }\end{array}$ & $\%$ & $\begin{array}{c}\tau_{3} \\
(\mathrm{~ns})\end{array}$ & $\%$ \\
\hline \multirow[t]{3}{*}{$1 \mathbf{a}(2.48 \mu \mathrm{M})$} & 500 & 530 & 5.8 & 78 & 1.3 & $22 \%$ & - & - \\
\hline & 500 & 550 & 5.8 & 82 & 1.8 & $18 \%$ & - & - \\
\hline & 500 & 570 & 5.9 & 77 & 3.0 & $23 \%$ & - & - \\
\hline \multirow[t]{3}{*}{ 1e $(1 \mu \mathrm{M})$} & 500 & 540 & 6.1 & 34 & 1.1 & $19 \%$ & 0.1 & 47 \\
\hline & 500 & 555 & 5.8 & 22 & 1.2 & $22 \%$ & 0.2 & 56 \\
\hline & 500 & 570 & 5.6 & 16 & 1.1 & $25 \%$ & 0.2 & 59 \\
\hline $\mathbf{1 a}(1.64 \mu \mathrm{M})$ & 525 & 555 & 5.1 & 64 & 1.9 & $36 \%$ & - & - \\
\hline $\mathbf{1 a}(1.93 \mu \mathrm{M})$ & 525 & 555 & 5.4 & 63 & 1.8 & $37 \%$ & - & - \\
\hline $1 \mathrm{a}(3.04 \mu \mathrm{M})$ & 525 & 555 & 4.7 & 53 & 1.7 & $47 \%$ & - & - \\
\hline $\mathbf{1 e}(0.52 \mu \mathrm{M})$ & 525 & 555 & 5.8 & 30 & 1.2 & $26 \%$ & 0.08 & 44 \\
\hline $\mathbf{1 e}(1 \mu \mathrm{M})$ & 525 & 555 & 5.7 & 24 & 1.1 & $24 \%$ & 0.2 & 52 \\
\hline $\mathbf{1 e}(2.3 \mu \mathrm{M})$ & 525 & 555 & 5.8 & 14 & 0.7 & $17 \%$ & 0.1 & 69 \\
\hline \multirow[t]{4}{*}{$\mathrm{EtOH} / \mathrm{H}_{2} \mathrm{O}(1: 10, \mathrm{v} / \mathrm{v})$} & 500 & 530 & 5.0 & 14 & 1.5 & $7 \%$ & 0.02 & 79 \\
\hline & 500 & 550 & 5.1 & 19 & 1.3 & $7 \%$ & 0.05 & 74 \\
\hline & 500 & 570 & 4.8 & 6 & 0.7 & $6 \%$ & 0.05 & 88 \\
\hline & 500 & 530 & 5.3 & 100 & - & - & - & - \\
\hline \multirow[t]{2}{*}{$\mathrm{EtOH}$} & 500 & 550 & 5.3 & 100 & - & - & - & - \\
\hline & 500 & 570 & 5.2 & 100 & - & - & - & - \\
\hline
\end{tabular}

[a] The fluorescence decays (Figures 7 and S6) were fitted with one, two or three exponential terms, as needed to obtain random residuals. [b] The concentration of $\mathbf{6}$ is listed in parentheses for the experiments with 1a and 1e. 

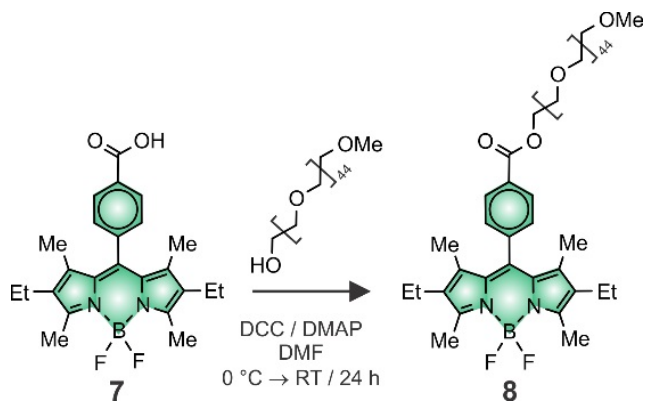

Figure S7. Synthesis of 8.

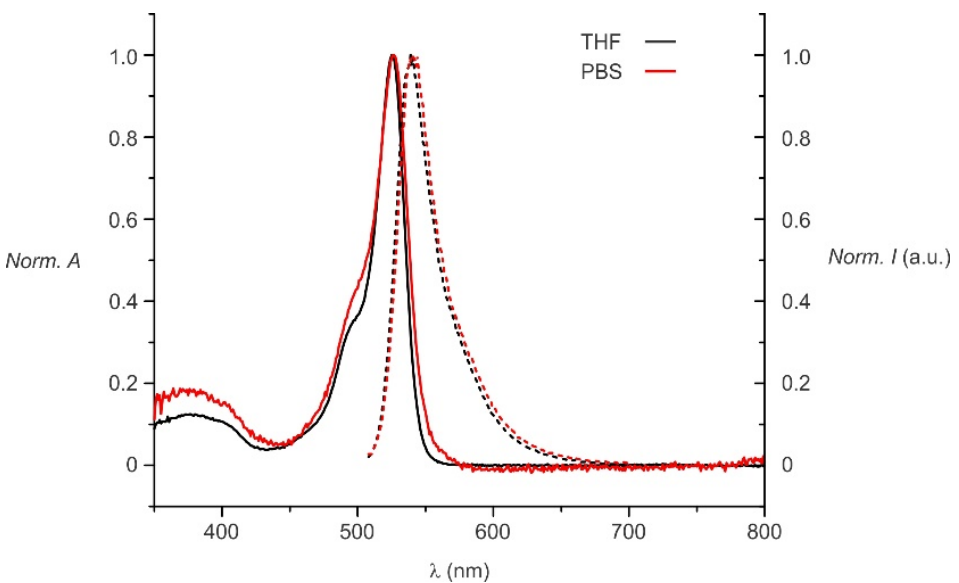

Figure S8. Normalized absorption and emission $\left(\lambda_{\mathrm{Ex}}=500 \mathrm{~nm}\right)$ spectra of 8 in THF or PBS at $25^{\circ} \mathrm{C}$.

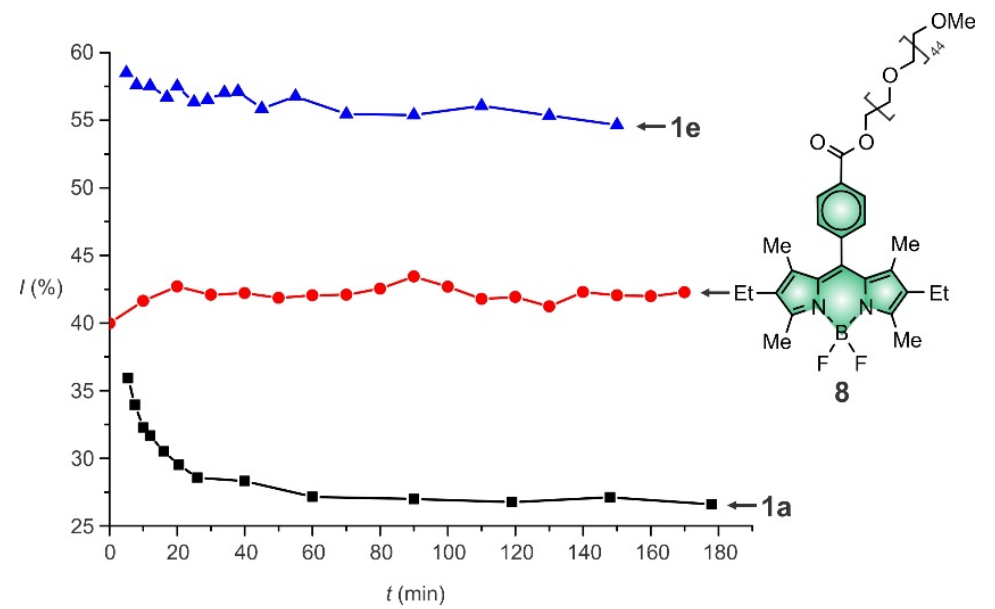

Figure S9. Temporal evolution of the emission intensity $\left(\lambda_{\mathrm{Ex}}=500\right.$ $\left.\mathrm{nm}, \lambda_{\mathrm{Em}}=540 \mathrm{~nm}\right)$ of nanoparticles of $\mathbf{1 a}$ or $\mathbf{1 e}$, containing $6(7.2 \mu \mathrm{M}$ for $1 \mathbf{a}$ and $2.8 \mu \mathrm{M}$ for $\mathbf{1 e}$ ), recorded in PBS at $25^{\circ} \mathrm{C}$ after the addition of $\mathrm{NaI}(0.1 \mathrm{mM})$ and reported relative to that measured in the absence of $\mathrm{NaI}$, together with the relative emission intensity of $8(0.1 \mathrm{mM})$ recorded after the addition of $\mathrm{NaI}(0.1 \mathrm{mM})$ under the same conditions. 


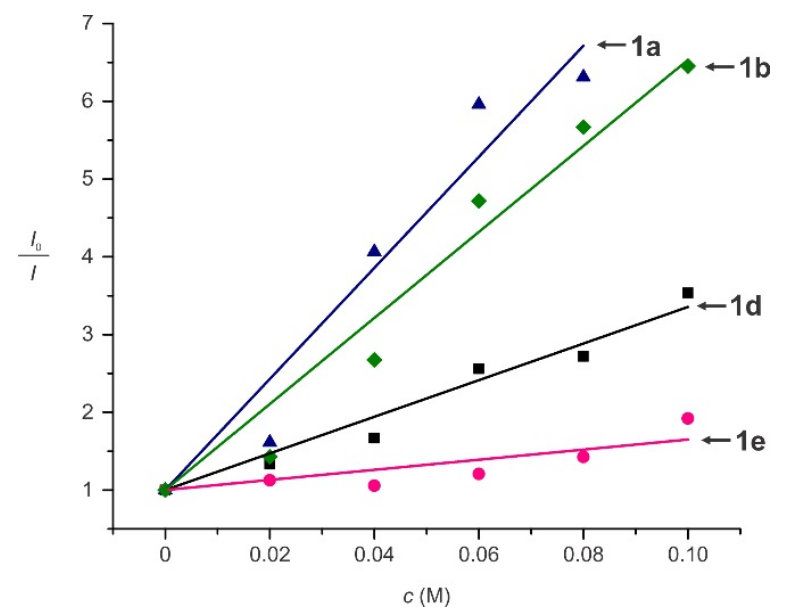

Figure S10. Plots of the relative emission intensity $\left(\lambda_{\mathrm{Ex}}=500 \mathrm{~nm}, \lambda_{\mathrm{Em}}=540 \mathrm{~nm}\right)$ of nanoparticles of 1a, 1b, 1d or 1e, containing $6(7.2 \mu \mathrm{M}$ for $1 \mathrm{a}, 7.8 \mu \mathrm{M}$ for 1b, $2.8 \mu \mathrm{M}$ for $\mathbf{1 d}$ and $2.8 \mu \mathrm{M}$ for $\mathbf{1 e}$ ), recorded in PBS at $25{ }^{\circ} \mathrm{C}$ after the addition of increasing amounts of NaI and storage in the dark for 3 hours, against the iodide concentration.

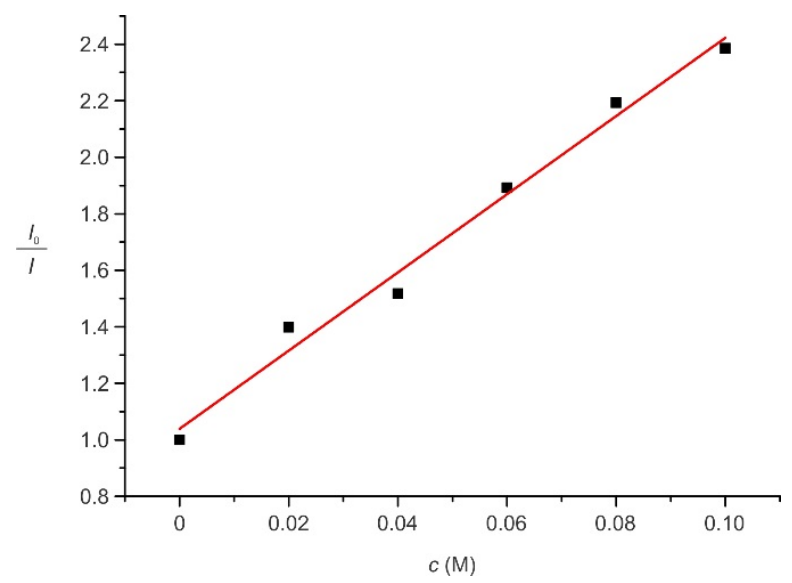

Figure S11. Plot of the relative emission intensity $\left(\lambda_{\mathrm{Ex}}\right.$ $\left.=500 \mathrm{~nm}, \lambda_{\mathrm{Em}}=540 \mathrm{~nm}\right)$ of $8(25 \mu \mathrm{M})$, recorded at 25 ${ }^{\circ} \mathrm{C}$ in PBS and the presence of increasing amounts of $\mathrm{NaI}$, against the iodide concentration. 
Determination of an Upper Bound for the Solubility of 6 in PBS. First, EtOH solutions of 6 at different concentrations were prepared and the photon count rate of each solution was measured in the same FCS instrument used to acquire the autocorrelation functions reported in the manuscript. The lowest concentration with a photon count rate three times above the background was $100 \mathrm{pM}$ and, therefore, it was concluded that the limit of detection of compound $\mathbf{6}$ in our instrument was 100 pM. Then, 6 was dissolved in PBS buffer and the photon count rate was measured in the same instrument. The result was indistinguishable from background, from which we conclude that the solubility of 6 in PBS is less than 100 pM.
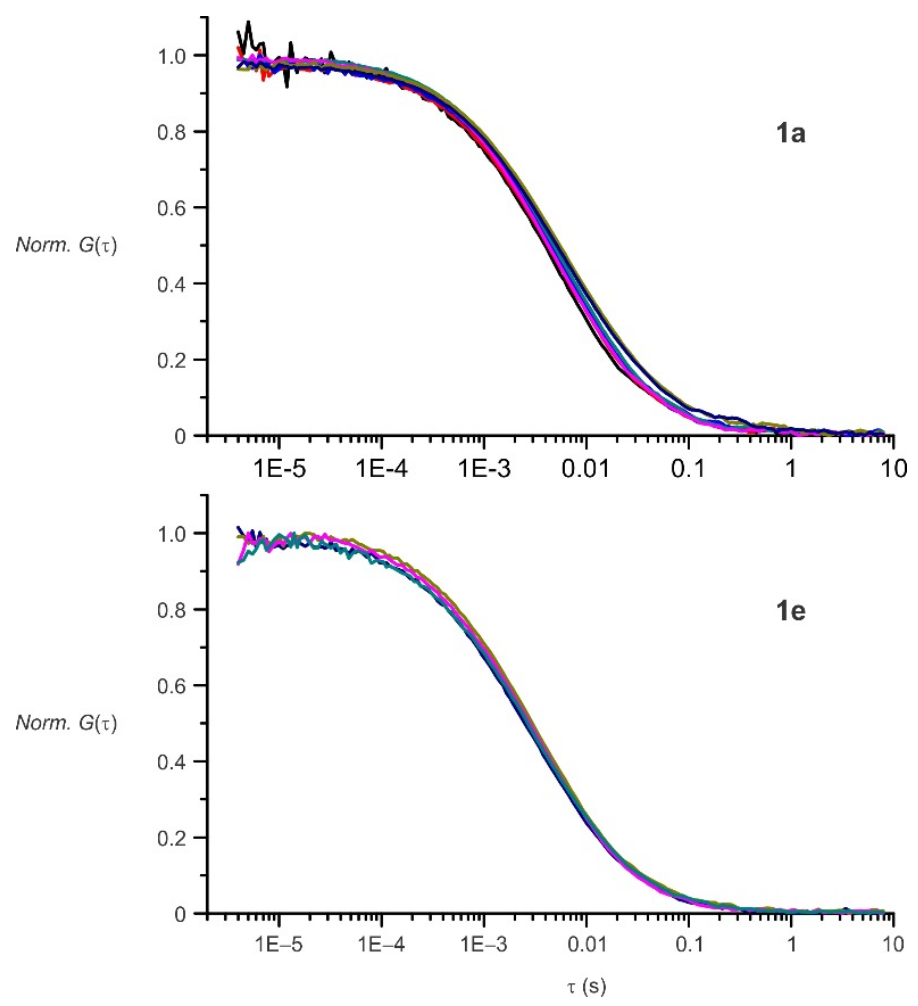

Figure S12. Autocorrelation decays of 6 incorporated into nanoparticles of either 1a or 1e. Samples were prepared using a concentration of $0.5 \mathrm{mg} \mathrm{mL}-1$ for the polymer. The concentration of guest, after filtration, was $2.4 \mu \mathrm{M}$ for $\mathbf{1 a}$ and $1.0 \mu \mathrm{M}$ for $1 \mathrm{e}$ The solutions were sequentially diluted using PBS buffer in 6 steps, until the concentration of polymer was $6.25 \mu \mathrm{g} \mathrm{mL} \mathrm{m}^{-1}$ (1:80) for $\mathbf{1 a}$ and $50 \mu \mathrm{g} \mathrm{mL} \mathrm{m}^{-1}$ (1:10) for $\mathbf{1 e}$ (the supramolecular hosts are not stable at lower polymer concentrations). Results show negligible changes in the autocorrelation function. 